counted for. Stitches removed on the eighth day. Wound healed by first intention. Up on the seventeenth day. Discharged well June 12, 1911.

Discharge Note. Abdominal wound firmly healed Uterus freely movable. No exudate. General condition much improved.

Pathological Report Specimen consists of a large tumor, weight 35 pounds. Its surface is smooth and in general it is somewhat nodular. Color is purplish and its surface bears numerous petechial hemorrhages. Moderately large blood vessels are visible on the surface. In shape it is roughly spherical; its lower surface is divided into three large nodular divisions, about $12 \mathrm{~cm}$. in width, separated by a deep groove. In one of these grooves there is attached a deep and broad ligament. A round strand of pinkish white tissue is also attached to the mass in one of these grooves. At one side the mass bears several cysts, the largest about $5 \mathrm{~cm}$. in diameter. On section the tissue is firm, pinkish in color and more or less lobulated throughout, having the appearance of a leiomyoma. An area about $6 \mathrm{~cm}$. in diameter filled with soft material apparently clotted with blood is situated in the substance of this tumor about $6 \mathrm{~cm}$. below the surface. The diameter of cross section is $30 \mathrm{~cm}$. Microscopic examination. Fibroma.-F. B. Mallory.

Mrs. M. as seen on Sept. 27, 1912. She stated that her weight two weeks after leaving the hospital was 109 , and that it now is 124 pounds, a gain of fifteen pounds. She feels finely and complains only of a pain in the right back, below the shoulder blade, the site of a fall in December before the operation. Questioning brought out the fact that periods, quite normal in every way, just as they were when she. was twenty, began in July, 1911. and have occurred regularly every month since and last three to four days. Examination shows a nine-inch median incision with moderate separation of recti in lower third. Vaginal examination shows stretched intact introitus. Cervix small. Uterus in partial descensus. Fundus anterior and small. No tenderness or thickening in either vault.

On July 15, 1913, she reported again in perfect health, having periods at monthly intervals as before.

There are several interesting points about this case which have made it worth reporting. First and foremost is the size of this true fibroma. There is every reason to doubt the histological nature of the Spiegelberg, Simpson and Curveiller tumors. They were obtained when exact pathological knowledge was quite incomplete and in all references to them $I$ have found a doubt in the mind of the writer as to their nature. But even though we grant them to have been fibromas, this case is unique in that the tumor was successfully removed at operation.

The second point of interest is that such a tumor could have been carried around with so little discomfort and lack of symptoms before operation. The patient complained only of a feeling of pressure under her ribs and of some difficulty in locomotion due to the excessive size of the tumor. None of her functions were disturbed; she had no orthopnea, no dyspnea, no urinary or bowel inconvenience. She had no menstrual disorders, and what we had supposed to be menopause had come easily and naturally five years before operation. In fact, she had been able to do her ordinary day's work up to the time of hospital entrance.

The fourth point of interest is the cessation of menstruation for three years previous to operation, with the re-establishment of absolutely regular periods after operation which have continued up to the time this is written.

I wish to thank Dr. Newell for his kindness in allowing me to report this case.

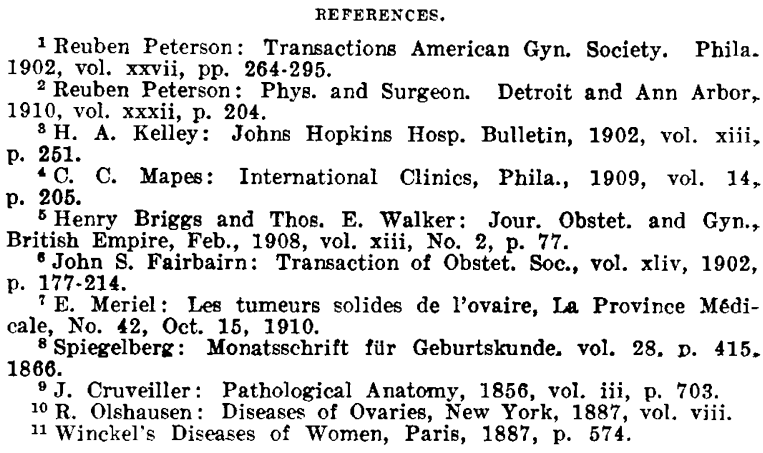

1 Reuben Peterson: Transactions American Gyn. Society. Phila. 1902, vol. xxvii, pp. 264-295.

2 Reuben Peterson: Phys. and Surgeon. Detroit and Ann Arbor, 910 , vol. xxxii, p. 204.

8 H. A. Kelley: Johns Hopkins Hosp. Bulletin, 1902, vol. xiii, p. 251.

205.

C. Mapes: International Clinics, Phila., 1909, vol. 14,

Henry Briggs and Thos, E. Walker: Jour. Obstet. and Gyn. ritish Empire, Feb., 1908, vol. xiii, No. 2, p. 77.

John S. Fairbairn: Transaction of Obstet. Soc., vol. xliv, 1902 , p. 177.214.

${ }^{7}$ E. Meriel: Les tumeurs solides de l'ovaire, La Province Médicale, No. 42, Oct. $15,1910$.

8 Spiegelberg: Monatsschrift für Geburtskunde. vol. 28, D. 415 ${ }^{8} \mathrm{~S}$
1866
${ }_{9} \mathrm{~J}$.

${ }^{9} \mathrm{~J}$. Cruveiller: Pathological Anatomy, 1856, vol. iii, p. 703.

10 Olshausen: Diseases of Ovaries, New York, 1887, vol viii. 11 Winckel's Diseases of Women, Paris, 1887, p. 574.

\section{TESTS FOR RENAL FUNCTION BASED UPON THE SELECTIVE EXCRETORY ACTIVITIES OF THE KIDNEY.*}

\author{
BY R. FITZ, M.D., BOSTON.
}

From the Medical Clinic of the Peter Bent Brigham Hosptial, Boston, Mass.

THe association between elinical and postmortem findings in nephritis has never been clearly defined. In 1905 Friedrich Müller suggested trying to correlate the signs of abnormal renal function as shown by various tests, with the different types of nephritis found during life and at autopsy. Since that time much work on the more exact study of renal function has been done, originating mainly from Schlayer and his co-workers.

Tests have been devised to study individual functions of the renal tubules and of the vessels of the glomeruli, based on the assumption that different portions of the renal structure have selective excretory activities. It must be emphasized that such are tests for renal function alone and cannot be made to prove the presence of constant anatomical lesions. By their use, however, renal physiology under pathological conditions can be studied more accurately than by usual clinical observations. It is the purpose of this paper to deseribe the technic of such tests and to state how information obtained by their use may be of value in the diagnosis, prognosis, and treatment of nephritis.

- Read at the annual meeting of The Massachusetts Medical Society, June 10, 1913. 
While under observation the patient is ordered a constant diet containing known amounts of fluids and salt. The total amount of fluid and sodium chloride excreted is followed from day to day. Experiments have shown that water and lactose when injected intravenously are put out mainly through the action of the glomerular vessels, while sodium chloride and potassium iodide come to the urine through the tubules. On different days an intravenous injection of lactose is given, or ten additional grams of sodium chloride by mouth, or onehalf a gram of potassium iodide by mouth. The manner of excretion of these substances is observed.

Two and one-half grams of pure lactose are dissolved in twenty-five cubic centimeters of freshly distilled water, placed in small cotton stoppered Erlenmeyer flasks and pasteurized for four hours daily on four successive days at a temperature between 75 to $80^{\circ} \mathrm{C}$. By this method the dose used is slightly over 2 grams of the sugar in twenty cubic centimeters of water. A fresh solution is used for each injection. Unless the lactose solution is so carefully prepared and sterilized, severe chills and other constitutional symptoms may follow its administration. After injection all the urine is collected at the end of four hours and every hour or two thereafter to twelve hours. Each specimen is tested for the presence of sugar with Nylander's reagent, using constant amounts of urine, solution, and a constant length of time for boiling. In this way excretion time is determined. Polarimetric readings must also be made to quantitate the total amount of sugar excreted. Normally sixty per cent. or more of the dose injected is regained in from four to six hours. Abnormality in excretion, both as for time and amount, affords an index to the degree of glomerular functional disturbance.

In health, water is excreted in amounts of about two-thirds of the fluid intake. When the glomerular function is abnormal, water excretion, as a rule, is markedly increased or diminished for long periods of time. The polyuria is considered to be due to a hypersensitive condition of the glomerular vessels by which they respond continuously to the small amounts of diuretic substances contained in food. The oliguria, on the other hand, is due to a torpid condition of these vessels as a result of which they are unable to excrete the usual amount of fluid. Which of these conditions exists is determined by the ratio of fluid output to intake. Further proof is found in the kidney's response to the diuretic stimulation of sodium chloride.

The excretion of salt is accomplished chiefly by the concentrative powers of the tubules. Normally in large amounts it is put out by one of two methods. If the sodium chloride is given without extra water it is excreted almost completely within twenty-four hours by increased concentration in the urine; if given with additional water it is excreted partially by increased concentration and partially by an increased amount of urine. In severe tubular injury with normal vessels added salt is retained in the body since the tubules are impermeable. Their functional capacity is determined by following in the urine, variations in the concentration curve of sodium chloride after it is ingested in large amounts without extra water. Salt is, however, under certain conditions a diuretic. In that type of glomerular injury characterized by hypersensitive vessels the added chloride produces an increased urinary outflow. Then it is excreted mainly in the excess of water, its concentration in the urine being increased or not depending on the condition of the tubular function.

Thus there are two distinct types of abnormal salt reaction. In the first added salt is not put out because the tubules are unable to concentrate it sufficiently and because the glomeruli are not hypersensitive. In the second, added salt is excreted promptly, mainly by diuresis, in part by increased concentration in the urine, because the glomeruli are hypersensitive, and the added salt acts as a diuretic. Between these two extreme types of salt excretion are variations depending upon differences in tubular function on the one hand, and glomerular function on the other.

Potassium iodide is excreted by the tubules. For the dose given the normal elimination time is sixty hours or less. The urine is tested for the presence of the drug at the end of fortyeight hours and every six hours later until the reaction for it is negative. Iodide in the urine is determined conveniently by Sandow's test. Two cubic centimeters of $2 \%$ sodium nitrate solution, 2 c.c. of $10 \% \mathrm{H}_{2} \mathrm{SO}_{4}$ and 30 c.c. of urine are mixed. To this is added a few cubic centimeters of chloroform. The whole is shaken. Purple or violet color appears in the chloroform if iodine is present. Theoretically, the more marked the degree of tubular disturbance, the more marked the delay in iodide excretion. Various observers, however, have found this test of little practical value in the determination of the renal function.

On the whole, by using these tests in the fashion outlined, it is possible to discover abnormalities in function on the part of the tubules and glomerular blood vessels of the kidney. Abnormal tubular function is shown by the inability of the kidney to increase the concentration of salt in the urine when an excess of salt is added to the diet and by a delay in the excretion time of potassium iodide. Abnormal glomerular function is shown by the inability of the kidney to excrete lactose in the usual time and quantity. Furthermore, abnormal glomerular function is of two types. The vessels are either hypersensitive, as shown by a constant polyuria increasing in response to the vascular stimulus of salt, or hyposensitive, as shown by a constant oliguria. The tests are of considerable quantitative value. In general, the 
severity of functional derangement shown by them corresponds with the clinical and anatomical severity of the disease. Cases studied by these methods can be grouped functionally into glomerular nephritides, tubular nephritides and a mixed form which shows functional derangement of both systems. The last group contains the majority of cases which are observed clinically.

The practical value of these tests lies in the ability afforded by them for more accurate diagnosis, prognosis and treatment of nephritis than can be attained by clinical observation alone. In many cases by their use it is possible to accuire positive evidence of a severe derangement of renal function before any clinical manifestations develop. Thus the tests are of value for the early diagnosis of nephritis. By repeating them at intervals over a long period of time it is possible to follow the progression of the disease through various stages of functional change. In this way, whether the renal function is returning to normal, remaining stationary or becoming worse can be determined. Thus the tests give valuable prognostic information. Finally, to some extent, the results of these tests offer a rational basis for treatment. It has been shown that the hypersensitive type of vascular lesion associated with polyuria is less severe than the oliguric type. Certain cases of the latter group can be stimulated into reactivity by small doses of caffein or digitalis derivatives given over a long period of time. The beneficial effect of a salt and water poor diet on renal patients unable to excrete salt or water has been recognized previously.

In conclusion it must be emphasized again that the lactose, water, salt and iodide tests study renal function without regard for the specific anatomical lesion producing the effects. By the use of these tests it is possible to follow certain phases of pathological renal physiology. Information obtained in this way is of greatest value in the early diagnosis of abnormal renal function. It may also be of value in prognosis and treatment.

\section{REFERENCES.}

Ashoff : Verh. der Deutsch. Path. Gesell., 1912, 199 ; Med. Klin., 1913 , vol. ix, p. 18.

Barker: American Jour. Med. Sciences, 1913, vol.. cxlv, p. 42.

Blum: Wien. Klin. Woch., 1912, vol. xxv, p. 443.

Christian: "The Relation of Functional Tests to Pathological Diagnosis," unpublished. Abstract, Jour. A. M. A., 1913, vol. lx, p. 1568 .

Conzen: Deutsch. Arch. f. Med., 1912, vol. cviii, p. 353 Eppinger and Barrenscheen: Wien. Med. Woch., 1912, vol. 1xii, pp. 1408, 1497.

Fischer: Deutsch. Arch. f. Klin. Med., 1913, clx, p. 469.

Hedinger: Deutsch. Arch. f. Klin. Med., 1910, vol. c, p. 305.

Janeway: Unpublished, Abst., Jour. A. M. A., 1913, vol. 1

Janeway: Unpublished, Abst., Jour. A. M. A., 1913, vol. 1x,
p. 1569.
Von Monakow: Deutsch. Arch. f. Klin. Med., 1911, vol. cii,

p. 248.

Miiller: Verh. der Deutsch. Path. Gesell., 1905, p. 64.

Von Noorden: Med. Klin., 1913, vol. 1x, p. 1 .

Pearce: Hill and Eisenbrey: Jour. Exp. Med., 1912, vol. xii, p. 196.

Rowntree: “The Prognostic Value of Studies of Renal Func-
tion." Unpublished, Abstract, Jour. A. M. A., 1913, vol. lx, p. 1568 .

Rowntree and Fitz: Arch. Int. Med., 1913, vol. xi, p. 258

Schlayer and Takayasu: Deutsch. Arch. f. Klin. Med., 19io, vol. xeviii, p. 17 ; 1911 , vol. ci, p. 354 .

Schlayer: Deutsch: Arch. f. Klin. Med., 1911, vol. ci, p. 333. 1911, vol. cii, p. 311, Verh. des Cong. f. Innere Med., 1912, vol.

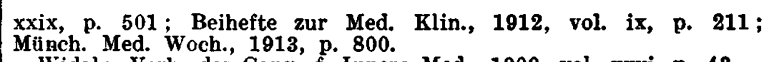

Widal: Verh. des Cong. f. Innere Med., 1909, vol. xxvi, p. 43.

\section{Oliniral Brpartment.}

\section{A CASE OF ANTHRAX.}

BY GEORGE A. BUCKLEY, M.D., WORCRSTER, MA88.,

IIouse Surgeon, Worcester City Hospital; Service of Dr. Homer Gage.

Miss K., a brush worker, 25 years of age, entered the hospital Nov. 27, 1912, with the history of having first noticed a "pimple" on her left eyebrow four days previously when her fellow workers called her attention to it. The "pimple" was a small, painless, red papule with no surrounding reaction, which rapidly increased in size. With the increase in size came swelling about it until in forty-eight hours the eye was closed and the forehead involved. About this time small blebs appeared on the eyelid, one of these being opened by the family physician, who reported obtaining clear serous fluid. The only other treatment consisted in poultices of boric acid solution and catharsis. There was no systemic disturbance except the day before entrance when the patient vomited an egg drink.

The family history contained one interesting fact: three years ago the patient's sister, a brush worker in the same factory, "had a pimple on her cheek; blood poisoning set in and she died in four days." No further information of this could be obtained.

The general physical examination revealed nothing of note, the temperature 101.6 ; pulse 124 , regular. There was some apprehension due to memory of her sister's fate.

The local examination showed the face and head distorted by a red swelling whose centre was the left eye, extending on the left over the forehead into the scalp as far back as the hair margin behind, and over the cheek into the neck below the ear; while on the right, it involved the nose, eyelids and forehead. Both eyes were closed by the edema. The margin of swelling extended about an inch beyond that of redness, and both were irregular and indefinite. The skin over the area was dull red, glossy, a little hot and slightly tender. The eyelid, remarkably swollen, was a deeper red than the surrounding region, and here also were several large blebs, flat and containing clear serous fluid. The base of the central of these which had been opened was blue-red and oozing a little serum. There was nowhere any fluctuation.

A smear from the fluid of one of the blebs showed gram-staining bacilli morphologically like anthracis. Cultures from the same later showed a pure growth of anthrax bacilli on several different culture media. Blood cultures taken at this time proved sterile.

The patient was isolated and five per cent. phenol was injected into the skin at different points in the red margin of the area, eighty minims being used in all. Warm poultices of corrosive sublimate (1-5000) were applied locally and changed frequently. Brandy and the tincture of digitalis were given regularly, and catharsis maintained with calomel and salines. 